\title{
The appetite suppressant d-fenfluramine reduces water intake, but not food intake, in activity-based anorexia
}

\author{
J J G Hillebrand ${ }^{1,2}$, A C M Heinsbroek ${ }^{1}$, M J H Kas ${ }^{1}$ and R A H Adan ${ }^{1}$ \\ ${ }^{1}$ Rudolf Magnus Institute of Neuroscience, Department of Pharmacology and Anatomy, University Medical Center Utrecht, Universtiteitsweg 100,3584 CG Utrecht, \\ The Netherlands \\ ${ }^{2}$ Altrecht - Rintveld Eating Disorders, Oude Arnehemseweg 260, 3705 BK, Zeist, The Netherlands
}

(Requests for offprints should be addressed to R A H Adan; Email: r.a.h.adan@med.uu.nl)

\begin{abstract}
Biochemical, genetic and imaging studies support the involvement of the serotonin (5-HT) system in anorexia nervosa. Activity-based anorexia (ABA) is considered an animal model of anorexia nervosa, and combines scheduled feeding with voluntary running wheel activity (RWA). We investigated the effect of d-fenfluramine (d-FEN) treatment on development and propagation of ABA. d-FEN is an appetite suppressant and acts on $5-\mathrm{HT}_{2 \mathrm{C}}$ receptors that are located on pro-opiomelanocortin (POMC) neurons in the arcuate nucleus of the hypothalamus. Since stimulation activation of the melanocortin system stimulates $A B A$, we hypothesized that d-FEN treatment enhances the development and propagation of ABA. Rats were exposed to the ABA model and chronically infused with d-FEN. Unexpectedly, d-FEN-treated $A B A$ rats did not reduce food intake or increase wheel running as compared with vehicle-treated $A B A$ rats. Furthermore d-FEN treatment did not affect body weight loss, hypothalamus-pituitary-adrenal axis activation, or starvation-induced hypothermia in ABA rats. POMC mRNA levels in d-FEN-treated rats were not different from vehicle-treated rats after one week of exposure to the ABA paradigm. However, d-FEN-treated ABA rats showed hypodypsia and increased plasma osmolality and arginine-vasopressin expression levels in the hypothalamus. We conclude that d-FEN treatment does not enhance ABA under the experimental conditions of this study, but strongly reduces water intake in $\mathrm{ABA}$ rats.
\end{abstract}

Journal of Molecular Endocrinology (2006) 36, 153-162

\section{Introduction}

Anorexia nervosa (AN) patients often show extreme dieting, body weight loss and hyperactivity (Kron et al. 1978, Casper et al. 1991, Walsh \& Devlin 1998). The serotonin (5-HT) system is involved in regulation of appetite and mood, and is the major biological system of interest in research on AN. For example, cerebrospinal fluid (csf) levels of 5-HT metabolite, 5-hydroxyindoleacetic acid (5-HIAA) are reduced in AN patients, while csf 5-HIAA levels are increased in recovered patients (Kaye et al. 1984, 1991). AN patients do not benefit from treatment with selective 5-HT reuptake inhibitors (SSRIs), but SSRI treatment appears to prevent relapse after weight restoration (Kaye et al. 2001). It was hypothesized by Kaye and colleagues that AN patients reduce food intake (thereby reducing dietary intake of the 5-HT precursor tryptophane) to diminish symptoms of their intrinsic dysphoric mood. Indeed, it was recently reported that plasma tryptophane levels are low in AN patients but increase following weight gain (Attia et al. 2005). Moreover, acute tryptophane depletion reduced anxiety levels in AN patients (Kaye et al. 2003). Association studies revealed polymorphisms in the promoter of the $5-\mathrm{HT}_{2 \mathrm{~A}}$ and $5-\mathrm{HT}_{2 \mathrm{C}}$ receptor that were associated with $\mathrm{AN}$ (Collier et al. 1997, Gorwood et al. 2002, Hu et al. 2003, Sorbi et al. 1998, Westberg et al. 2002), although this could not be confirmed by others (Campbell et al. 1998, Nacmias et al. 1999). In addition, results from positron emission tomography (PET) studies showed that AN patients have reduced $5-\mathrm{HT}_{2 \mathrm{~A}}$ receptor binding in the mesial temporal lobe, which persists after recovery (Frank et al. 2002).

The activity-based anorexia (ABA) model is considered an animal model of AN. In this model, food access restricted to one hour per day in combination with voluntary access to running wheels is reported to result in hyperactivity, hypophagia and severe body weight loss (Hall \& Hanford 1954, Routtenberg \& Kuznesof 1967). In addition to hyperactivity, rats show an altered activity pattern and develop extensive activity prior to food access, which is referred to as food-anticipatory activity (FAA) (Mistlberger 1994). Furthermore, it was shown before that ABA rats are hypothermic (Hillebrand et al. $2005 a$ ) and have an increased activation of the hypothalamus-pituitary-adrenal (HPA) axis (Burden et al. 1993, Kas et al. 2003). In an alike semi-starvationinduced hyperactivity (SIH) model (which uses $60 \%$ of 
baseline food intake/day instead of $1 \mathrm{~h}$ food access/day), 5 -HT turnover was increased in the medial basal hypothalamus (Broocks et al. 1991).

The melanocortin (MC) system plays an important role in energy homeostasis (Cone 1999, Schwartz et al. 2000). Expression levels of pro-opiomelanocortin (POMC) were decreased in the arcuate nucleus (ARC) of the hypothalamus of rats that were exposed to the ABA paradigm for one week (Kas et al. 2003). Recently, we observed that stimulation of the $\mathrm{MC}$ system by chronic treatment with the endogenous agonist $\alpha$-melanocyte stimulating hormone $(\alpha-\mathrm{MSH}$, a neuropeptide derived from POMC), decreased food intake and increased FAA, body weight loss and activation of the HPA axis in ABA rats (Hillebrand et al. 2005b). Previously, we also showed that $\operatorname{AgRP}_{(83-132)}$ treatment prevented selfstarvation in ABA rats, by influencing food intake, locomotor activity and body temperature (Kas et al. 2003).

D-fenfluramine (d-FEN) stimulates 5-HT release and blocks its reuptake (Rowland \& Carlton 1986, Gibson et al. 1993, McCann et al. 1997). The 5-HT $1 \mathrm{~B}$ and $5-\mathrm{HT}_{2 \mathrm{C}}$ receptor are the main candidate receptors mediating the inhibitory control of 5-HT on food intake. Both these receptors also seem to be involved in d-FEN-induced hypophagia (Dourish 1995, Tecott et al. 1995, Simansky 1996, Glifton et al. 2000, Vickers et al. 2003). 5- $\mathrm{HT}_{1 \mathrm{~B}}$ as well as $5-\mathrm{HT}_{2 \mathrm{C}}$ deficient mice showed an attenuated response to d-FEN-induced hypophagia, although they still had d-FEN-induced locomotor deficits at high doses (Lucas et al. 1998, Vickers et al. 1999, Lee et al. 2004). Hypophagic actions of d-FEN were reduced by co-treatment with a $5-\mathrm{HT}_{1 \mathrm{~B}}$ or $5-\mathrm{HT}_{2 \mathrm{C}}$ receptor antagonist (Vickers et al. 2001, Simansky \& Nicklous 2002). Yet other studies showed that mainly the $5-\mathrm{HT}_{2 \mathrm{C}}$ receptor plays an important role in d-FENinduced hypophagia (Vickers et al. 2001, Glifton et al. 2003). It was recently demonstrated that $5-\mathrm{HT}_{2 \mathrm{C}}$ receptors are located on POMG neurons in the ARC. Activation of POMC neurons by d-FEN resulted in an increased firing rate of these neurons and subsequently in an anorexic response (Heisler et al. 2002).

Given that interference with the MC system influences the development and propagation of ABA (Kas et al. 2003, Hillebrand et al. 2005b) and since d-FEN acts upstream of the MG system (Heisler et al. 2002), we hypothesized that d-FEN treatment enhances ABA by reducing food intake and increasing RWA, specifically FAA. Although d-FEN-induced hypophagia in ABA rats was reported before (Rieg et al. 1994), effects of d-FEN treatment on running wheel activity (RWA) have not been observed. In the present study we investigated the effect of d-FEN treatment on development and propagation of ABA further, by analyzing several characteristics of ABA such as ingestive behaviour (food and water intake), RWA (including FAA), body temperature and activation of the HPA axis as well as hypothalamic POMC gene expression.

\section{Materials and methods}

\section{Rats}

Female outbred Wistar WU rats $n=44$, Harlan, Horst, The Netherlands) were individually housed in a temperature and humidity controlled room $\left(21 \pm 2{ }^{\circ} \mathrm{C}\right)$ under a 12:12 h dark:light cycle (ZT12=lights off). The ethical committee on use and care of animals of Utrecht University approved all described procedures.

\section{Drugs}

For in vivo administration, d-FEN (Servier, Paris, France) was dissolved in sterile isotonic saline and was chronically (continuous during 1 week) infused subcutaneously (sc) at a dose of $10 \mathrm{mg} / \mathrm{kg} /$ day using osmotic minipumps $(0.5 \mu \mathrm{l} / \mathrm{h}$, Alzet, model 1007D, DURECT Corporation, Cupertino, CA, USA). No adverse reactions to chronic administration of this dose of dFEN were reported before (Reig et al. 1994).

\section{Surgical procedures}

One week after arrival, rats received transmitters (TA10TA-F40 Data Sciences International, St Paul, $\mathrm{MN}, \mathrm{USA}$ ) in the abdominal cavity under fentanyl/ fluanisone $\left(\right.$ Hypnorm $^{\circledR}$, Janssen Pharmaceutica, Beerse, Belgium, $0 \cdot 1 \mathrm{ml} / 100 \mathrm{~g}$ intramuscular) and midazolam (Dormicum ${ }^{\circledR}$, Hoffman-LaRoche, Mijdrecht, The Netherlands, $\quad 0.05 \mathrm{ml} / 100 \mathrm{~g}$ intraperitoneal) anaesthesia (ABA experiment only). After surgery, rats were treated with buprenorphin $\left(\right.$ Temgesic $^{\circledR}$, Schering-Plough, Maarssen, The Netherlands, $0.05 \mathrm{ml} / 100 \mathrm{~g} \mathrm{sc}$ ) and saline $(1 \mathrm{ml} \mathrm{sc})$.

For chronic vehicle or d-FEN infusions, all rats were anaesthetized by fentanyl/fluanisone as described above and the right flank was shaved. An osmotic minipump containing vehicle or d-FEN $(10 \mathrm{mg} / \mathrm{kg} /$ day $)$ was sc. placed into the flank region of the rat after overnight incubation at $37^{\circ} \mathrm{C}$.

\section{Experimental set-up}

\section{d-Fenfluramine treatment in ad libitum fed rats}

In this experiment, the effects of chronic d-FEN treatment in ad libitum fed sedentary rats were investigated. Two weeks after arrival (day -1$), 14$ rats were divided into two groups (vehicle and d-FEN), matched for body weight (average body weight day -1 : $238 \cdot 2 \pm 2 \cdot 5 \mathrm{~g}$ ). Osmotic minipumps were implanted as described before. After surgery (day 0, ZT 12), food and 
water were ad libitum available. Each day, body weight, food intake and water intake were measured at the end of the light phase (ZT11). Rats were decapitated after 1 week (day 6, ZT11). Trunk blood was collected into lithium-heparin containing tubes (Sarstedt, Nümbrecht, Germany) after adding $83 \mu \mathrm{mol}$ EDTA and $1 \mathrm{mg}$ aprotonin. Plasma was separated and frozen at $-20^{\circ} \mathrm{C}$. Brains were rapidly removed, quickly frozen in cold $\left(-35^{\circ} \mathrm{C}\right.$ ) isopentane and stored at $-80^{\circ} \mathrm{C}$. Adrenal glands were isolated and weighed.

\section{d-Fenfluramine treatment in activity-based anorexia rats}

In this experiment, the effects of chronic d-FEN treatment on development and propagation of $\mathrm{ABA}$ were investigated. After 2 weeks of recovery from the implantation of transmitters, 16 rats were placed into cages with running wheels for a training period of 10 days (day -10 to day -1 ) with ad libitum food and water access. RWA was continuously registered using a Gage Registration Program (Department of Biomedical Engineering, UMC Utrecht, The Netherlands). On day -1 , rats were divided into two groups (vehicle and d-FEN), matched for body weight (average body weight day $-1: 227 \cdot 7 \pm 2 \cdot 7 \mathrm{~g}$ ) and baseline RWA (average day-4 : day-1: 4024.5 $\pm 510 \cdot 9$ revolutions/day). Transmitters were switched on (by magnetic field induction) to allow continuous assessment of body temperature and locomotor activity (LMA). Osmotic minipumps were implanted as described before. After surgery (day 0, ZT12), food was removed, while water remained ad libitum available. Food was available during the first hour of the dark phase (ZT12 to ZT13) (day 1-6). Each day, body weight, food intake and water intake were measured. Rats were decapitated after 1 week (day 6, ZT11) as described above.

\section{In situ hybridization}

Cryosections (coronal, $20 \mu \mathrm{m}$ ) of the hypothalamus of all rats were sliced using a cryostat (Leica, Rijswijk, The Netherlands) and thaw-mounted onto RNAse free Superfrost slides (Menzel, Brannschweig, Germany). The slides were stored at $-80{ }^{\circ} \mathrm{C}$ until processed for in situ hybridization. Sections were fixed in $4 \%$ paraformaldehyde (PFA) in phosphate-buffered saline (PBS) for $10 \mathrm{~min}$, washed in PBS, pre-treated with $0 \cdot 25 \%$ acetic anhydride in $0 \cdot 1 \mathrm{M}$ triethanolamine, washed again in PBS and dehydrated in graded ethanol followed by $100 \%$ chloroform and $100 \%$ ethanol. ${ }^{33}$ P-labelled antisense RNA probes were made using a $350 \mathrm{bp}$ rat POMC cDNA fragment and a $205 \mathrm{bp}$ argininevasopressin (AVP) cDNA fragment (exon G) (Kas et al. 2003). The sections were hybridized overnight at $72{ }^{\circ} \mathrm{C}$ with $1 \times 10^{6}$ c.p.m. probe in buffer containing $50 \%$ deionized formamide, $2 \times$ standard saline citrate $(\mathrm{SSC})$,
$10 \%$ dextrane sulphate, $1 \times$ Denhardt's solution, $5 \mathrm{mM}$ EDTA and $10 \mathrm{mM}$ phosphate buffer, after $5 \mathrm{~min}$ heating at $80^{\circ} \mathrm{C}$. After hybridization, the sections were washed in $5 \times \mathrm{SSC}$ (short, $\left.72{ }^{\circ} \mathrm{C}\right)$ and $0.2 \times \operatorname{SSC}(2 \mathrm{~h}$, $72{ }^{\circ} \mathrm{G}$ ) and dehydrated in graded ethanol with $3 \mathrm{M}$ ammoniumacetate. Sections were exposed to X-ray films (Kodak Bio-Max MR, Amersham) for 5 days. The films were developed and expression of POMC (in the ARC) and AVP (in the paraventricular nucleus (PVN) and supraoptic nucleus (SON)) was semi-quantitatively analyzed using a calibration curve and the Microcomputer Imaging Device (MCID) (Imaging Research Inc., St Catharines, Ontario, Canada).

\section{Radioimmunoassay}

Plasma levels of corticosterone, adrenocorticotropic hormone (ACTH) and leptin were analyzed by radioimmunoassay (RIA). A commercially available rat corticosterone RIA kit (ICN Biochemicals, Costa Mesa, CA, USA) and rat leptin RIA kit (Linco Research, St Charles, MO, USA, detection limit $0.5 \mathrm{ng} / \mathrm{ml}$ ) were used. Assays were performed according to the manufacturer's protocol. Plasma ACTH was measured using a specific rabbit antiserum directed to the midportion of ACTH, which was kindly provided by $\mathrm{Dr}$ G B Makara (Budapest, Hungary). Synthetic human ACTH $_{(1-39)}$ (Peninsula Laboratories, Belmont, CA, USA) was labelled with ${ }^{125} \mathrm{I}$ and used as a tracer (Nijsen et al. 2000).

\section{Plasma osmolality}

Plasma osmolality was measured by U-Diagnostics (Utrecht, The Netherlands) using a Fiske ${ }^{\circledR} 2400$ multi-sample osmometer according to the manufacturer's protocol (Indumed, Dendermonde, Belgium).

\section{Data analysis}

All data are presented as mean \pm S.E. Data were analyzed using SPSS 11.5 (SPSS Inc., Amsterdam, The Netherlands) for Windows and were controlled for normality and homogeneity. For all measurements, baseline levels were not significantly different between groups. Basal body temperature was analyzed as average body temperature (of telemetric recordings) during 30 min of inactivity in the early light phase (ZT0-ZT3). Relative body weight, food intake, water intake, RWA (ABA only), LMA (ABA only) and basal body temperature (ABA only) were analyzed by general linear model (GLM) repeated measures using Huynh-Feldt correction for Mauchlys sphericity effects and followed by $t$-tests. Cumulative RWA and LMA (ABA only), cumulative water and food intake, HPA axis activation, plasma osmolality and ISH data were analyzed by 
$t$-tests. Differences were considered significant at $P<0 \cdot 05$

\section{Results}

\section{d-Fenfluramine treatment in ad libitum fed sedentary rats}

Ad libitum fed sedentary rats were treated with $10 \mathrm{mg} / \mathrm{kg}$ /day d-FEN by osmotic minipumps for one week. This treatment significantly influenced food intake $($ day $\mathrm{F}(6,72)=85 \cdot 95 ; P<0 \cdot 001$, day $\times$ treatment $\mathrm{F}(6,72)=$ 16.06; $P<0 \cdot 001)$. d-FEN-treated rats had a reduced cumulative $($ day $0-6)$ food intake $(\mathrm{t}(12)=7 \cdot 05 ; P<0 \cdot 001)$ as compared with vehicle-treated rats (Figure 1A).

Relative body weight was affected by chronic d-FEN treatment $($ day $\mathrm{F}(6,72)=14 \cdot 40 ; P<0 \cdot 001$, day $\times$ treatment $\mathrm{F}(6,72)=2 \cdot 52 ; P=0 \cdot 03) . \mathrm{d}-\mathrm{FEN}$-treated rats had a lower relative body weight following 1 week as compared with vehicle-treated rats $(\mathrm{t}(12)=4 \cdot 16 ; P=0 \cdot 001)$ (Figure 1B). Body weight loss was also evident from reduced plasma leptin levels following d-FEN treatment $(\mathrm{t}(11)=2 \cdot 97$; $P=0 \cdot 01)$ (Table 1).

Water intake was also influenced by d-FEN treatment (day $\mathrm{F}(6,66)=9 \cdot 96 ; \quad P<0 \cdot 001$, day $\times$ treatment $\mathrm{F}(6,66)=14 \cdot 41 ; P<0 \cdot 001)$. Cumulative $($ day $0-6)$ water intake $(\mathrm{t}(11)=3.56 ; P=0.004)$ was significantly reduced in d-FEN-treated rats $(73.2 \pm 4.5 \%)$ as compared with vehicle-treated rats $(100 \cdot 0 \pm 5 \cdot 2 \%)$ (Figure 1C). However, plasma osmolality was not changed following 1 week of d-FEN treatment $(\mathrm{t}(12)=-1.77$; not significant, n.s.) and neither were AVP gene expression levels in the PVN $(\mathrm{t}(9)=-0 \cdot 80 ;$ n.s. $)$ and $\operatorname{SON}(\mathrm{t}(9)=0 \cdot 98 ; \mathrm{n} . \mathrm{s})$ (Table 1). In contrast, POMC gene expression levels in the ARG were significantly reduced following one week of d-FEN treatment $(\mathrm{t}(9)=2 \cdot 93 ; P=0 \cdot 03)$.

The unaffected plasma ACTH $(\mathrm{t}(12)=-2 \cdot 17 ; P=0 \cdot 07)$, plasma corticosterone $(\mathrm{t}(12)=1.51 ; \mathrm{n} . \mathrm{s})$ and relative adrenal weights $(\mathrm{t}(12)=-1.91 ; \mathrm{n} . \mathrm{s})$ indicated unchanged activity of the HPA axis (Table 1).

\section{d-Fenfluramine treatment in $A B A$ rats}

Since an effective dose of d-FEN was determined in ad libitum fed rats, this dose was used in $\mathrm{ABA}$ rats in order to influence the development and propagation of ABA. All rats developed hyperactivity following introduction of scheduled feeding. Substantial RWA was observed at the end of the light phase (ZT9-ZT12), which is referred to as food-anticipatory activity (FAA). However, FAA was not affected by d-FEN treatment $($ day $\mathrm{F}(6,84)=15 \cdot 76 ; P<0 \cdot 001$, day $\times$ treatment $\mathrm{F}(6,84)=$ $0 \cdot 27$; n.s). Total daily RWA (day $\mathrm{F}(6,84)=32 \cdot 34$; $P<0 \cdot 001$, day $\times$ treatment $\mathrm{F}(6,84)=0.51 ;$ n.s $)$ was also not influenced by d-FEN treatment. In addition, cumulative FAA (day 0-6) $(\mathrm{t}(14)=1 \cdot 26$; n.s) and cumulative daily
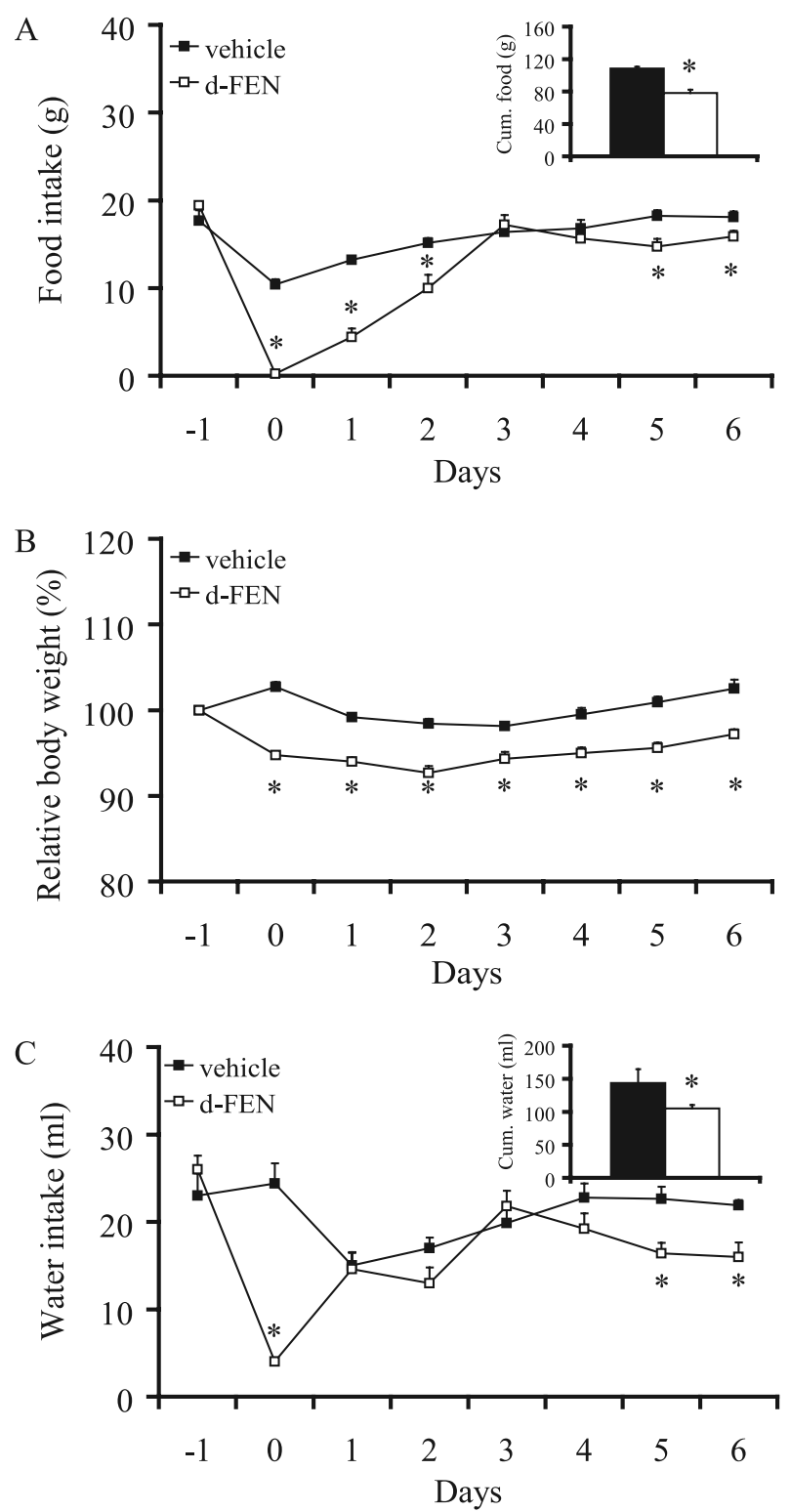

Figure $1 \mathrm{~d}$-Fenfluramine treatment in ad libitum fed rats. (A) Daily food intake, (B) daily relative body weight (\% of day $-1)$ and $(C)$ daily water intake in ad libitum fed rats treated with vehicle (closed/black, $n=8$ ) or d-fenfluramine (open/white, $n=6$ ). Small panels in $A$ and $C$ represent cumulative values. GLM repeated measurements or $t$-tests. * indicates significantly different from vehicle, $P<0.05$.

RWA (day 0-6) $(t(14)=0.99 ; n . s)$ were not altered by d-FEN treatment (Figure 2A+B). Daily LMA, as measured by telemetric recordings, was not affected by d-FEN treatment over time (day $\mathrm{F}(6,78)=11 \cdot 66$; $P<0 \cdot 001, \mathrm{~F}(6,78)=0 \cdot 20 ; \mathrm{n} . \mathrm{s})$, nor was daily cumulative LMA $($ day $0-6)(\mathrm{t}(13)=0 \cdot 48 ; \mathrm{n} . \mathrm{s})$ (data not shown).

Food intake of ABA rats was not affected by one week of d-FEN treatment (day $\mathrm{F}(5,70)=53 \cdot 05 ; P<0 \cdot 001$, day 
Table $1 \mathrm{~d}$-Fenfluramine treatment in ad libitum fed rats: peripheral and central parameters

\begin{tabular}{|c|c|c|}
\hline & Vehicle & d-FEN \\
\hline Osmolality (mOsm/kg) & $305 \cdot 0 \pm 3 \cdot 1$ & $330 \cdot 2 \pm 13 \cdot 9$ \\
\hline Leptin (ng/ml) & $2 \cdot 6 \pm 0 \cdot 2$ & $1 \cdot 7 \pm 0 \cdot 2^{*}$ \\
\hline ACTH $(\mathrm{pg} / \mathrm{ml})$ & $62 \cdot 4 \pm 6 \cdot 1$ & $101 \cdot 7 \pm 17 \cdot 1$ \\
\hline Corticosterone $(\mu \mathrm{g} / \mathrm{dl})$ & $23 \cdot 7 \pm 3 \cdot 6$ & $16 \cdot 7 \pm 2 \cdot 2$ \\
\hline Adrenal weight (\% bodyweight day 6 ) & $0.026 \pm 0.001$ & $0.029 \pm 0.002$ \\
\hline AVP-SON (arbitrary units) & $100 \cdot 0 \pm 7 \cdot 7$ & $91 \cdot 8 \pm 4 \cdot 1$ \\
\hline AVP-PVN (arbitrary units) & $100 \cdot 0 \pm 4 \cdot 0$ & $83 \cdot 6 \pm 2 \cdot 4$ \\
\hline POMC-ARC (arbitrary units) & $100 \cdot 0 \pm 6 \cdot 8$ & $76 \cdot 9 \pm 2 \cdot 7^{*}$ \\
\hline
\end{tabular}

Plasma osmolality, plasma leptin, plasma adrenocorticotropic hormone (ACTH), plasma corticosterone levels, relative adrenal weight and gene expression levels (arbitrary units) of arginine-vasopressin (AVP) (analyzed in the supraoptic nucleus (SON) and paraventricular nucleus $(\mathrm{PVN})$ ), and pro-opiomelanocortin (POMC) (analyzed in arcuate nucleus (ARC)), in ad libitum fed rats treated with vehicle $(n=8)$ or d-fenfluramine $(n=6)$. T-tests, *indicates significantly different from vehicle, $P<0.05$.

$\times$ treatment $\mathrm{F}(5,70)=0 \cdot 30 ;$ n.s). In addition, cumulative food intake (day 1-6) was not different among $\mathrm{d}$-FEN-treated and vehicle-treated ABA rats $(\mathrm{t}(14)=$ $1 \cdot 66$; n.s) (Figure 2G).

Similar to food intake and RWA, relative body weight was unaffected following one week of d-FEN treatment $($ day $\mathrm{F}(6,84)=383 \cdot 35 ; P<0 \cdot 001$, day $\times$ treatment $\mathrm{F}(6,84)=$ $1 \cdot 55$; n.s) (Figure 2D). The final relative body weight of d-FEN-treated ABA rats was not different from vehicle-treated $\mathrm{ABA}$ rats $(\mathrm{t}(14)=0.90 ; \mathrm{n} . \mathrm{s})$ and plasma leptin levels were below detection limits $(<0.5 \mathrm{ng} / \mathrm{ml})$ in both ABA groups.

The disbalance between energy intake and expenditure in $\mathrm{ABA}$ rats resulted in severe hypothermia. However, basal body temperature, measured during inactivity in the early light phase (ZT0-ZT3), was not affected by one week of d-FEN treatment (day $\mathrm{F}(6,84)=28 \cdot 35 ; \quad P<0 \cdot 001)$, day $\times$ treatment $\quad \mathrm{F}(6,84)=$ $0 \cdot 27$; n.s) (Figure 2E).

Activation of the HPA-axis, as frequently seen in ABA rats, was not affected by d-FEN treatment. Plasma ACTH levels $(\mathrm{t}(13)=0.62$; n.s.), plasma corticosterone $(t(13)=0.87$; n.s. $)$ levels and relative adrenal weight $(t(14)=0.49$; n.s.) were not different between d-FENtreated rats and vehicle-treated rats following one week of treatment (Table 2).

Thus, d-FEN treatment did not influence any of the characteristics of ABA rats mentioned before. However, d-FEN treatment significantly affected water consumption (day $(\mathrm{F}(6,78)=3 \cdot 20 ; P=0 \cdot 03$, day $\times$ treatment $\mathrm{F}(6,78)=$ $2 \cdot 63 ; P=0 \cdot 05$ ). Cumulative daily water intake (day $0-6$ ) was dramatically reduced in d-FEN-treated rats $(58 \cdot 4 \pm 3 \cdot 4 \%)$ as compared with vehicle-treated rats $(100 \cdot 0 \pm 7 \cdot 3 \%)(\mathrm{t}(13)=0 \cdot 49 ; P<0 \cdot 001)$ (Figure $2 \mathrm{~F})$. This corresponded with increased plasma osmolality following one week of d-FEN treatment in $\mathrm{ABA}$ rats $(\mathrm{t}(13)=-2 \cdot 27 ; \quad P=0 \cdot 04)$ (Table 2). In addition, gene expression levels of AVP were increased in the SON $(\mathrm{t}(9)=-2 \cdot 30 ; \quad P=0 \cdot 04)$ and in the PVN $(\mathrm{t}(9)=-2 \cdot 71$; $P=0.03)$ following one week of d-FEN treatment. In contrast, POMG gene expression in the ARC was not affected by d-FEN treatment $(\mathrm{t}(12)=1.23$; n.s.) (Table 2).

\section{Discussion}

We showed that chronic d-FEN treatment did not change food intake and RWA in ABA rats. Body weight loss, HPA axis activation and hypothermia were also not affected by d-FEN treatment. However, d-FEN treatment significantly reduced water intake in ABA rats.

The absence of hypophagia in d-FEN-treated ABA rats was unexpected, since it was reported earlier that (one week of) d-FEN treatment reduced food intake in rats (Vickers et al. 2000, Rieg et al. 1994). This discrepancy might be explained by differences in experimental setup of the current and previous studies, such as duration of food access ( $1 \mathrm{~h}$ vs $1.5 \mathrm{~h}$ ), running wheel access during feeding (access vs no access), gender (female vs male), age of the rats ( \pm 12 weeks vs 9 weeks) and strain of the rats (Wistar vs Sprague Dawley). Moreover, the experimental approach of the two ABA studies was different; while we examined the effects of d-FEN treatment on development and propagation of ABA during one week of treatment, Rieg et al. (1994) focussed the analysis on the day when $25 \%$ body weight loss was reached.

Whilst our study was being completed, another study was published, which showed that daily injections of d-FEN enhanced ABA (Atchley \& Eckel 2005). This was caused by decreased food intake as well as by additional effects on energy expenditure, most likely being increased brown adipose tissue activity and increased 

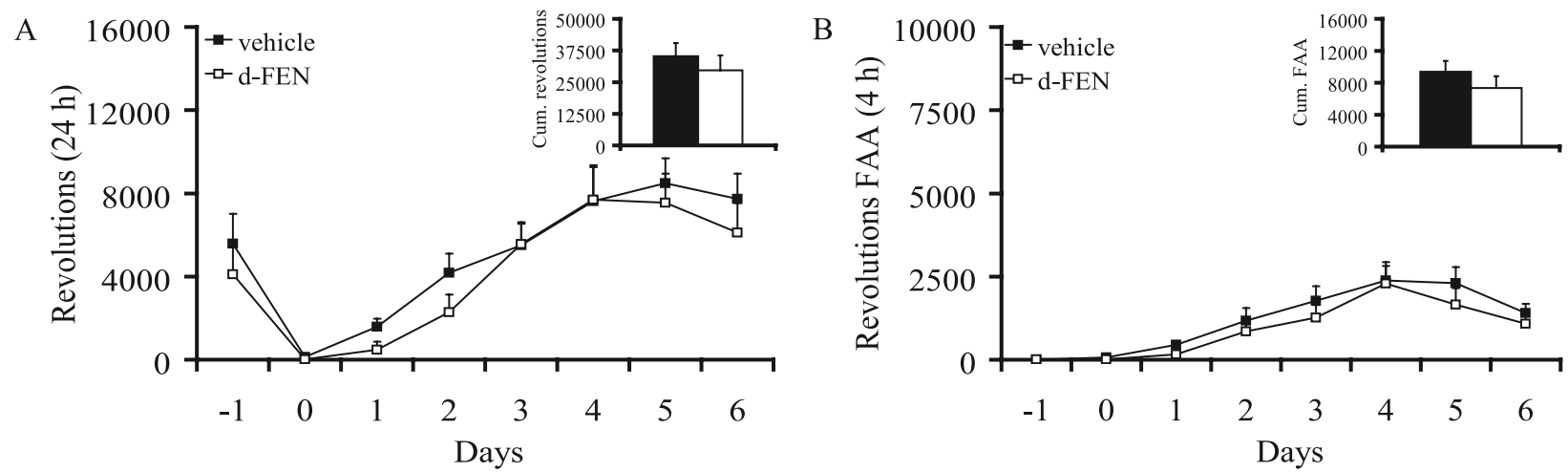

C
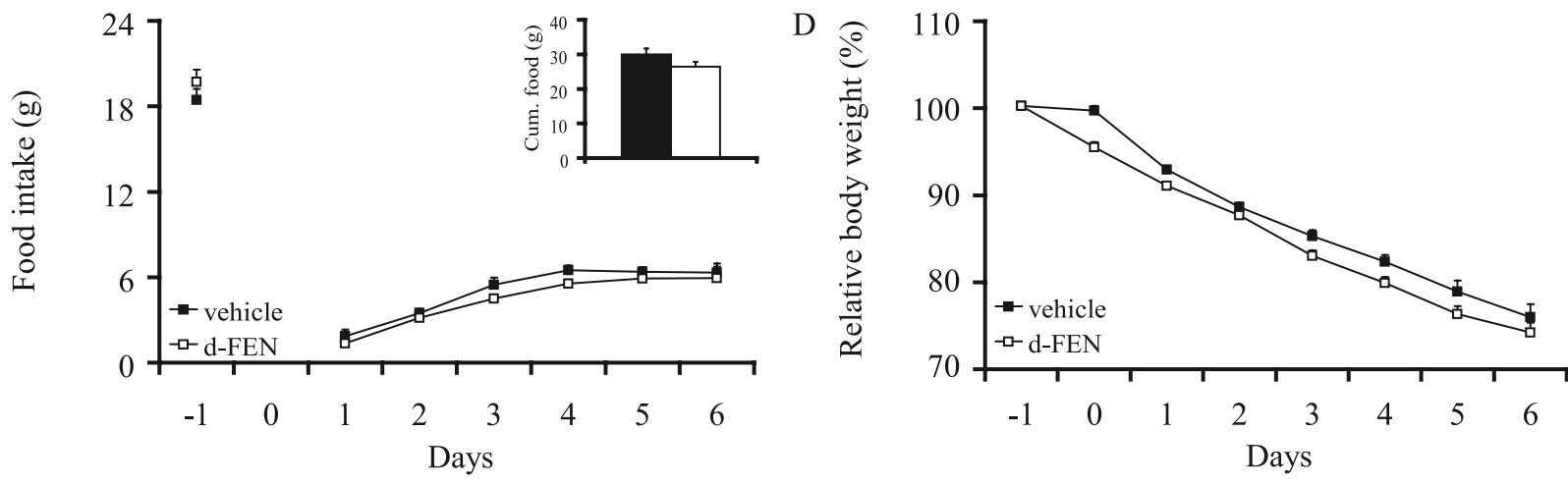

E

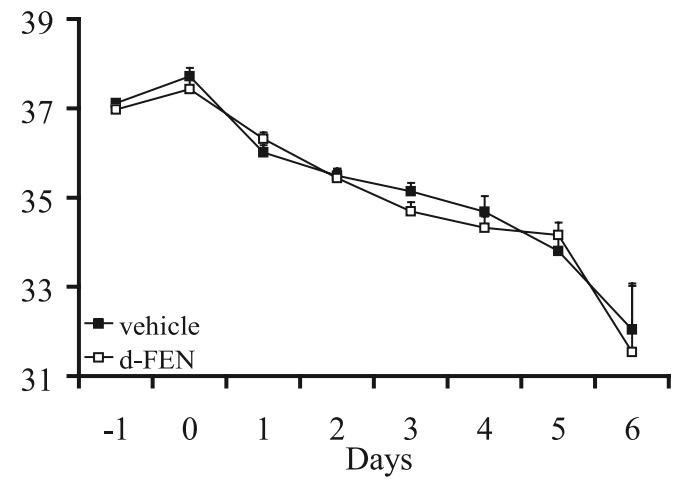

$\mathrm{F}$

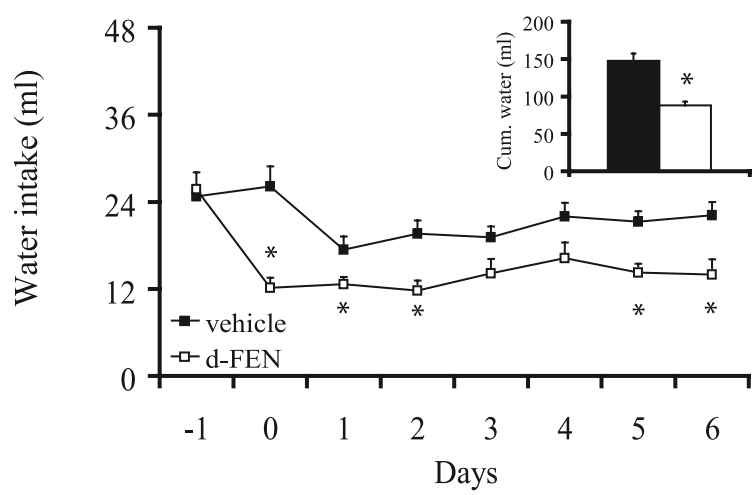

Figure $2 \mathrm{~d}$-Fenfluramine treatment in ABA rats. (A) Total daily running wheel activity, (B) daily running wheel activity during $4 \mathrm{~h}$ preceding food access (FAA), (C) daily food intake, (D) daily relative body weight (\% of day -1$)$, (E) daily body temperature during rest and $(F)$ daily water intake in $A B A$ rats treated with vehicle (closed/black, $n=8$ ) or d-fenfluramine (open/white, $n=8)$. Small panels in A-C, F represent cumulative values. GLM repeated measurements or $t$-tests. * indicates significantly different from vehicle, $P<0.05$.

lipid oxidation. In the present experiment, we found no evidence for anorexic effects of d-FEN in ABA rats. However, d-FEN-treated ad libitum fed rats reduced food intake showing efficacy of the dose $(10 \mathrm{mg} / \mathrm{kg} /$ day $)$ and treatment method (osmotic minipumps) used. Hence, the present results suggest that d-FEN-induced appetite suppression is overruled by physiological signals of starvation in ABA rats. Differences between the current study and the study of Atchley \& Eckel (2005) might be explained by differences in experimental setup, such as the method of administration of d-FEN (osmotic minipump vs daily injections), dosage $(10 \mathrm{mg} / \mathrm{kg} /$ day vs $0.5 \mathrm{mg} / \mathrm{kg} /$ day), duration of food access (1 h vs $2 \mathrm{~h}$ ), strain of the rats (Wistar vs Long Evans) and possibly the stage of the oestrous cycle at the start of treatment. In an additional experiment, we treated ABA rats with a lower dose of d-FEN ( $1 \mathrm{mg} / \mathrm{kg} /$ day by osmotic minipump) for one week. However, we found that this dose of d-FEN did not affect any parameter of ABA and also did not reduce food intake in ad libitum fed rats (data not shown). 
Table 2 d-Fenfluramine treatment in activity-based anorexia rats: peripheral and central parameters

\begin{tabular}{|c|c|c|}
\hline & Vehicle & d-FEN \\
\hline Osmolality (mOsm/kg) & $309 \cdot 8 \pm 7 \cdot 1$ & $340 \cdot 6 \pm 11 \cdot 3^{*}$ \\
\hline Leptin (ng/ml) & n.d. & n.d. \\
\hline АCTH (pg/ml) & $147.5 \pm 21.0$ & $133 \cdot 3 \pm 8 \cdot 6$ \\
\hline Corticosterone $(\mu \mathrm{g} / \mathrm{dl})$ & $33 \cdot 7 \pm 3 \cdot 7$ & $29 \cdot 3 \pm 3 \cdot 0$ \\
\hline Adrenal weight ( $\%$ bodyweight day 6$)$ & $0.043 \pm 0.004$ & $0.040 \pm 0.002$ \\
\hline AVP-SON (arbitrary units) & $100 \cdot 0 \pm 16 \cdot 3$ & $161 \cdot 3 \pm 21 \cdot 8$ \\
\hline AVP_PVN (arbitrary units) & $100 \cdot 0 \pm 5 \cdot 8$ & $184 \cdot 8 \pm 27 \cdot 8^{*}$ \\
\hline POMC-ARC (arbitrary units) & $100 \cdot 0 \pm 15 \cdot 3$ & $78 \cdot 3 \pm 8 \cdot 7$ \\
\hline
\end{tabular}

Plasma osmolality, plasma leptin, plasma adrenocorticotropic hormone (ACTH), plasma corticosterone levels, relative adrenal weight and gene expression levels (arbitrary units) of arginine-vasopressin (AVP) (analyzed in the supraoptic nucleus (SON) and paraventricular nucleus $(\mathrm{PVN})$ ), and pro-opiomelanocortin (POMC) (analyzed in arcuate nucleus (ARC)), in ABA rats treated with vehicle $(n=8)$ or d-fenfluramine $(n=8)$. T-tests, *indicates significantly different from vehicle, $P<0.05$. n.d., not detectable.

In the present study, we observed no effect of chronic d-FEN treatment on RWA or LMA in ABA rats. Total daily activity, activity during the dark phase (data not shown) as well as FAA, were not affected by d-FEN treatment. This corresponds with the two earlier studies, although in these studies total RWA was examined, and not specifically FAA (Rieg et al. 1994, Atchley \& Eckel 2005). Moreover, effects of d-FEN on RWA, especially on FAA, could have been easily missed by Atchley \& Eckel (2005) due to the timing of the d-FEN injections. Previously others reported reduced LMA and RWA in rats treated with d-FEN or other $5-\mathrm{HT}_{2 \mathrm{C}}$ preferring agonists during positive and negative energy balance (Aulakh et al. 1988, Kennett \& Curzon 1988, Wilckens et al. 1992). Chronic fluoxetine (a SSRI) treatment also reduced RWA, whereas chronic parachlorophenylalanine (a tryptophane hydroxylase inhibitor) treatment increased RWA in semi-starved (SIH) rats (Altemus et al. 1996). From the aforementioned, it could thus be hypothesized that d-FEN treatment reduces wheel running in $\mathrm{ABA}$ rats. However, d-FEN treatment activates $5-\mathrm{HT}_{2 \mathrm{C}}$ receptors, that are located on POMC neurons (Heisler et al. 2002) and we showed before that chronic $\alpha$-MSH infusion increased wheel running, specifically FAA, in ABA rats (Hillebrand et al. 2005b). These data suggest that d-FEN treatment would increase wheel running in ABA rats. Altogether, unaffected wheel running following d-FEN treatment in the present as well as previous ABA experiments suggest the existence of compensating mechanisms.

Activation of the MC system following d-FEN treatment could not be confirmed. D-FEN treatment did not lead to a reduction in food intake or increased FAA as was observed following $\alpha$-MSH treatment. Moreover, d-FEN treatment did not increase (but tended to decrease) POMC mRNA expression after one week of treatment. Absence of early effects of chronic d-FEN treatment on development of ABA might be explained by already over-active POMC neurons during early days of ABA. We recently found transient up-regulation of POMC gene expression during early days of ABA (Hillebrand et al. 2005c. Following a few days of food restriction, compensating signals associated with severe negative energy balance could possibly override the putative d-FEN-induced stimulation of POMC neurons. In fact, in ad libitum fed rats a significant down-regulation of POMC was observed, which can be explained as a counter-regulatory response to a decrease in food intake and body weight. From this study it thus becomes clear that effects of acute and chronic treatment of d-FEN on e.g. POMC expression levels and food intake are not easily comparable (Choi et al. 2002, Heisler et al. 2002). Further studies should therefore be aimed at further analyzing actual 5-HT levels and 5- $\mathrm{HT}_{2 \mathrm{C}} \mathrm{R}$ binding on POMG neurons during development of ABA following chronic d-FEN treatment.

In the present study, water intake was measured to investigate specificity of d-FEN-induced effects on ingestive behaviour. Total daily water intake was reduced in $\mathrm{ABA}$ rats during the whole treatment period. As a consequence, plasma osmolality and mRNA levels of AVP, a neuropeptide involved in regulation of extra cellular fluid balance, were increased after 1 week of treatment. Ad libitum fed rats also showed a reduction of water intake following d-FEN treatment. However, this reduction was smaller than observed in ABA rats, and plasma osmolality and AVP gene expression were not changed following 1 week of treatment. Since rats often combine food and water intake, the reduction of water intake in ABA rats may be exaggerated as compared with ad libitum fed rats which eat more.

Strong and long-lasting effects of d-FEN treatment on water intake have not been reported before. A modest decrease in water intake was observed following acute 
injections of d-FEN, and during early days of long-term d-FEN treatment (Fletcher 1988, Roth \& Rowland 1998, Vickers et al. 2003), and seems to be mediated by $5-\mathrm{HT}_{2 \mathrm{C}}$ or $5-\mathrm{HT}_{1 \mathrm{~B}}$ receptors (Clifton et al. 2000, Lee et al. 2002). The MC system seems not to be involved in the effect of d-FEN on water intake; chronic intracerebroventricular (icv) $\alpha-\mathrm{MSH}$ treatment does not lead to reduced water intake of $\mathrm{ABA}$ rats $(\mathrm{J} \mathrm{J} \mathrm{G}$ Hillebrand, M J H Kas, R A H Adan, 2005).

D-FEN-induced changes in AVP gene expression have not been described before, whereas d-FEN-induced increases in plasma AVP levels are generally known (Iovino \& Steardo 1985, Max 1994, Saydoff et al. 1996). Regarding plasma hyperosmolality (van Tol et al. 1987, Amaya et al. 1999) in ABA rats and the only modest activation of c-fos in AVP neurons following d-FEN treatment (Javed et al. 1999, Mikkelsen et al. 1999), the up-regulation of AVP expression is probably an indirect result of hypodypsia and not of a direct effect of d-FEN on AVP neurons. Nevertheless there are also indications that plasma AVP levels are at least partly mediated via $5-\mathrm{HT}_{2 \mathrm{C}} \mathrm{R}$ and the angiotensin system (Saydoff et al. 1996). Increased AVP release by the pituitary following acute d-FEN or 5-HT treatment can be reduced by inhibiting angiotensin II production or by antagonizing angiotensin 1 or $5-\mathrm{HT}_{2 \mathrm{AC}}$ receptors. In the present experiment we did not measure AVP release (but central AVP expression) and used chronic d-FEN treatment instead of acute treatment (which is not easily comparable), therefore, we consider increased AVP expression as a secondary response to hypodipsia, which is observed to a greater extent in ABA rats than in ad libitum fed rats.

We observed no changes in $1 \mathrm{~h}$ food intake, RWA, body weight loss or HPA axis activation in d-FENtreated ABA rats. Strikingly, these three important parameters of ABA are influenced by chronic $\alpha-\mathrm{MSH}$ treatment. In addition, POMC mRNA expression levels in $\mathrm{ABA}$ rats were not increased (but tended to be decreased) following one week of d-FEN treatment. A prolonged decrease in water intake was observed in d-FEN-treated ABA rats, which corresponded with increased plasma osmolality and increased AVP gene expression. d-FEN was an effective appetite reducing agent for treating obesity. However, it was withdrawn from the market in 1997 because of potential harmful side effects, such as pulmonary hypertension and unusual valvular morphology and regurgitation (GuyGrand 1995, Connolly et al. 1997, MacLean 1999). Yet no information is available on its effects on fluid intake, although patients often complained of a dry mouth and drowsiness (Connolly et al. 1997, Bray \& Greenway 1999). We conclude that d-FEN treatment results in a strong and prolonged reduction of water intake in food-restricted running rats, but does not enhance the development and propagation of ABA in this study.

\section{Acknowledgements}

G van Dijk and AJW Scheurink are gratefully acknowledged for their scientific contributions. JJGH was supported by NWO grant 9033175, The Netherlands. The authors declare that there is no conflict of interest that would prejudice this study.

\section{References}

Altemus M, Glowa JR, Galliven E, Leong YM \& Murphy DL 1996 Effects of Serotonergic Agents on Food-Restriction-Induced Hyperactivity. Pharmacology \& Biochemistry of Behaviour $\mathbf{5 3}$ 123-131.

Amaya F, Tanaka M, Tamada Y, Tanaka Y, Nilaver G \& Ibata Y 1999 The Influence of Salt Loading on Vasopressin Gene Expression in Magno- and Parvocellular Hypothalamic Neurons: an Immunocytochemical and in Situ Hybridization Analysis. Neuroscience 89 515-523.

Atchley DP \& Eckel LA 2005 Fenfluramine Treatment in Female Rats Accelerates the Weight Loss Associated With Activity-Based Anorexia. Pharmacology \& Biochemisry of Behaviour 80 273-279.

Attia E, Wolk S, Cooper T, Glasofer D \& Walsh BT 2005 Plasma Tryptophan During Weight Restoration in Patients With Anorexia Nervosa. Biology of Psychiatry $57674-678$.

Aulakh CS, Wozniak KM, Hill JL \& Murphy DL 1988 Long-Term Imipramine Treatment Differentially Affects Fenfluramine-Induced Suppression of Food Intake and Locomotor Activity. Pharmacology \& Biochemistry of Behaviour 31 97-101.

Bray GA \& Greenway FL 1999 Current and Potential Drugs for Treatment of Obesity. Endocrine Reviews 20 805-875.

Broocks A, Schweiger U \& Pirke KM 1991 The Influence of Semistarvation-Induced Hyperactivity on Hypothalamic Serotonin Metabolism. Physiology of Behaviour 50 385-388.

Burden VR, White BD, Dean RG \& Martin RJ 1993 Activity of the Hypothalamic-Pituitary-Adrenal Axis Is Elevated in Rats With Activity-Based Anorexia. Fournal of Nutrition 123 1217-1225.

Campbell DA, Sundaramurthy D, Markham AF \& Pieri LF 1998 Lack of Association Between 5-HT2A Gene Promoter Polymorphism and Susceptibility to Anorexia Nervosa. Lancet 351 499.

Casper RC, Schoeller DA, Kushner R, Hnilicka J \& Gold ST 1991 Total Daily Energy Expenditure and Activity Level in Anorexia Nervosa. American fournal of Clinical Nutrition 53 1143-1150.

Choi S, Jonak EM, Simpson L, Patil V \& Fernstrom JD 2002 Intermittent, Chronic Fenfluramine Administration to Rats Repeatedly Suppresses Food Intake Despite Substantial Brain Serotonin Reductions. Brain Research 928 30-39.

Clifton PG, Lee MD \& Dourish CT 2000 Similarities in the Action of Ro 60-0175, a 5-HT2C Receptor Agonist and D-Fenfluramine on Feeding Patterns in the Rat. Psychopharmacology (Berlin) 152 256-267.

Clifton PG, Lee MD, Somerville EM, Kennett GA \& Dourish CT 2003 5-HT1B Receptor Knockout Mice Show a Compensatory Reduction in 5-HT2C Receptor Function. European fournal of Neuroscience 17 185-190.

Collier DA, Arranz MJ, Li T, Mupita D, Brown N \& Treasure J 1997 Association Between 5-HT2A Gene Promoter Polymorphism and Anorexia Nervosa. Lancet 350412.

Cone RD 1999 The Central Melanocortin System and Energy Homeostasis. Trends in Endocrinological Metabolism 10 211-216.

Connolly HM, Crary JL, McGoon MD, Hensrud DD, Edwards BS, Edwards WD \& Schaff HV 1997 Valvular Heart Disease Associated With Fenfluramine-Phentermine. New England Fournal of Medicine 337 581-588. 
Dourish CT 1995 Multiple Serotonin Receptors: Opportunities for New Treatments for Obesity? Obesity Research 3 Suppl 4 449S-462S.

Fletcher PJ 1988 The Effects of D-Fenfluramine on Saccharin Intake and Preference, and on Food and Water Intake. Pharmacology $\Xi^{\circ}$ Biochemistry of Behaviour 29 687-691.

Frank GK, Kaye WH, Meltzer CC, Price JC, Greer P, McConaha C \& Skovira K 2002 Reduced 5-HT2A Receptor Binding After Recovery From Anorexia Nervosa. Biology of Psychiatry 52 896-906.

Gibson EL, Kennedy AJ \& Curzon G 1993 D-Fenfluramine- and D-Norfenfluramine-Induced Hypophagia: Differential Mechanisms and Involvement of Postsynaptic 5-HT Receptors. European Fournal of Pharmacology 242 83-90.

Gorwood P, Ades J, Bellodi L, Cellini E, Gollier DA, Di Bella D, Di Bernardo M, Estivill X, Fernandez-Aranda F, Gratacos M et al. 2002 The 5-HT(2A) -1438 G/A Polymorphism in Anorexia Nervosa: a Combined Analysis of 316 Trios From Six European Centres. Molecular Psychiatry 7 90-94.

Guy-Grand B 1995 Clinical Studies With Dexfenfluramine: From Past to Future. Obesity Research 3 491S-496S.

Hall JF \& Hanford PV 1954 Activity As a Function of a Restricted Feeding Schedule. Fournal of Comparative Physiology \& Psychology 47 362-363.

Heisler LK, Cowley MA, Tecott LH, Fan W, Low MJ, Smart JL, Rubinstein M, Tatro JB, Marcus JN, Holstege H et al. 2002 Activation of Central Melanocortin Pathways by Fenfluramine. Science 297 609-611.

Hillebrand JJ, de Rijke CE, Brakkee JH, Kas MJ \& Adan RA 2005a Voluntary Access to a Warm Plate Reduces Hyperactivity in Activity-Based Anorexia. Physiology of Behaviour 85 151-157.

Hillebrand JJ, Kas MJ \& Adan RA 2005b a-MSH Enhances Activity-Based Anorexia. Peptides 26 1690-1696.

Hillebrand JJG, Kas MJH, Scheurink AJW, van Dijk G \& Adan RAH 2005c AgRP (83-132) and SHU9119 differently affect activity-based anorexia. European Neuropsychopharmacolgy (In press).

$\mathrm{Hu}$ X, Giotakis O, Li T, Karwautz A, Treasure J \& Collier DA 2003 Association of the 5-HT2c Gene With Susceptibility and Minimum Body Mass Index in Anorexia Nervosa. Neuroreport 14 781-783.

Iovino M \& Steardo L 1985 Effect of Substances Influencing Brain Serotonergic Transmission on Plasma Vasopressin Levels in the Rat. European Fournal of Pharmacology 113 99-103.

Javed A, Kamradt MC, Van de Kar LD \& Gray TS 1999 D-Fenfluramine Induces Serotonin-Mediated Fos Expression in Corticotropin-Releasing Factor and Oxytocin Neurons of the Hypothalamus, and Serotonin-Independent Fos Expression in Enkephalin and Neurotensin Neurons of the Amygdala. Neuroscience 90 851-858.

Kas MJ, van Dijk G, Scheurink AJ \& Adan RA 2003 Agouti-Related Protein Prevents Self-Starvation. Molecular Psychiatry 8 235-240.

Kaye WH, Ebert MH, Raleigh M \& Lake R 1984 Abnormalities in CNS Monoamine Metabolism in Anorexia Nervosa. Archives of General Psychiatry 41 350-355.

Kaye WH, Gwirtsman HE, George DT \& Ebert MH 1991 Altered Serotonin Activity in Anorexia Nervosa After Long-Term Weight Restoration. Does Elevated Cerebrospinal Fluid 5-Hydroxyindoleacetic Acid Level Correlate With Rigid and Obsessive Behavior? Archives of General Psychiatry $\mathbf{4 8}$ $556-562$.

Kaye WH, Nagata T, Weltzin TE, Hsu LK, Sokol MS, McConaha C, Plotnicov KH, Weise J \& Deep D 2001 Double-Blind Placebo-Controlled Administration of Fluoxetine in Restrictingand Restricting-Purging-Type Anorexia Nervosa. Biology of Psychiatry $49644-652$.

Kaye WH, Barbarich NC, Putnam K, Gendall KA, Fernstrom J, Fernstrom M, McConaha CW \& Kishore A 2003 Anxiolytic
Effects of Acute Tryptophan Depletion in Anorexia Nervosa. International Journal of Eating Disorders 33 257-267.

Kennett GA \& Curzon G 1988 Evidence That MCPP May Have Behavioural Effects Mediated by Central 5-HT1C Receptors. British Fournal of Pharmacology 94 137-147.

Kron L, Katz JL, Gorzynski G \& Weiner H 1978 Hyperactivity in Anorexia Nervosa: a Fundamental Clinical Feature. Comprehensive Psychiatry 19 433-440.

Lee MD, Kennett GA, Dourish CT \& Clifton PG 2002 5-HT1B Receptors Modulate Components of Satiety in the Rat: Behavioural and Pharmacological Analyses of the Selective Serotonin 1B Agonist CP-94,253. Psychopharmacology (Berlin) 164 49-60.

Lee MD, Somerville EM, Kennett GA, Dourish CT \& Clifton PG 2004 Reduced Hypophagic Effects of D-Fenfluramine and the 5-HT(2C) Receptor Agonist MCPP in 5-HT(1B) Receptor Knockout Mice. Psychopharmacology (Berlin) 176 39-49.

Lucas JJ, Yamamoto A, Scearce-Levie K, Saudou F \& Hen R 1998 Absence of Fenfluramine-Induced Anorexia and Reduced C-Fos Induction in the Hypothalamus and Central Amygdaloid Complex of Serotonin 1B Receptor Knock-Out Mice. Fournal of Neuroscience 18 5537-5544.

MacLean MR 1999 Pulmonary Hypertension, Anorexigens and 5-HT: Pharmacological Synergism in Action? Trends in Pharmacological Science $20490-495$.

Max MB 1994 Treatment of Post-Herpetic Neuralgia: Antidepressants. Annals of Neurology 35 S50-S53.

McCann UD, Yuan J, Hatzidimitriou G \& Ricaurte GA 1997 Selective Serotonin Reuptake Inhibitors Dissociate Fenfluramine's Anorectic and Neurotoxic Effects: Importance of Dose, Species and Drug. Fournal of Pharmacology \& Experimental Therapy $\mathbf{2 8 1}$ 1487-1498.

Mikkelsen JD, Jensen JB, Engelbrecht T \& Mork A 1999 D-Fenfluramine Activates Rat Oxytocinergic and Vasopressinergic Neurons Through Different Mechanisms. Brain Research 851 247-251.

Mistlberger RE 1994 Circadian Food-Anticipatory Activity: Formal Models and Physiological Mechanisms. Neuroscience Biobehavior Reviews 18 171-195.

Nacmias B, Ricca V, Tedde A, Mezzani B, Rotella CM \& Sorbi S 1999 5-HT2A Receptor Gene Polymorphisms in Anorexia Nervosa and Bulimia Nervosa. Neuroscience Letters 277 134-136.

Nijsen MJ, Croiset G, Stam R, Bruijnzeel A, Diamant M, De Wied D \& Wiegant VM 2000 The Role of the CRH Type 1 Receptor in Autonomic Responses to Corticotropin- Releasing Hormone in the Rat. Neuropsychopharmacology 22 388-399.

Rieg TS, Maestrello AM \& Aravich PF 1994 Weight Cycling Alters the Effects of D-Fenfluramine on Susceptibility to Activity-Based Anorexia. American Fournal of Clinical Nutrition 60 494-500.

Roth JD \& Rowland NE 1998 Efficacy of Administration of Dexfenfluramine and Phentermine, Alone and in Combination, on Ingestive Behavior and Body Weight in Rats. Psychopharmacology (Berlin) 137 99-106.

Routtenberg A \& Kuznesof AW 1967 Self-Starvation of Rats Living in Activity Wheels on a Restricted Feeding Schedule. Fournal of Comparative Physiology \& Psychology $64414-421$.

Rowland NE \& Carlton J 1986 Neurobiology of an Anorectic Drug: Fenfluramine. Progress in Neurobiology 27 13-62.

Saydoff JA, Rittenhouse PA, Carnes M, Armstrong J, Van de Kar LD \& Brownfield MS 1996 Neuroendocrine and Cardiovascular Effects of Serotonin: Selective Role of Brain Angiotensin on Vasopressin. American Fournal of Physiology 270 E513-E521.

Schwartz MW, Woods SC, Porte D, Jr., Seeley RJ \& Baskin DG 2000 Central Nervous System Control of Food Intake. Nature $\mathbf{4 0 4}$ $661-671$

Simansky KJ 1996 Serotonergic Control of the Organization of Feeding and Satiety. Behavioural Brain Research 73 37-42. 
Simansky KJ \& Nicklous DM 2002 Parabrachial Infusion of D-Fenfluramine Reduces Food Intake. Blockade by the 5-HT(1B) Antagonist SB-216641. Pharmacology \& Biochemistry of Behaviour 71 681-690.

Sorbi S, Nacmias B, Tedde A, Ricca V, Mezzani B \& Rotella CM 1998 5-HT2A Promoter Polymorphism in Anorexia Nervosa. Lancet 3511785.

Tecott LH, Sun LM, Akana SF, Strack AM, Lowenstein DH, Dallman MF \& Julius D 1995 Eating Disorder and Epilepsy in Mice Lacking 5-HT2c Serotonin Receptors. Nature 374 $542-546$.

van Tol HH, Voorhuis DT \& Burbach JP 1987 Oxytocin Gene Expression in Discrete Hypothalamic Magnocellular Cell Groups Is Stimulated by Prolonged Salt Loading. Endocrinology 120 71-76.

Vickers SP, Clifton PG, Dourish CT \& Tecott LH 1999 Reduced Satiating Effect of D-Fenfluramine in Serotonin 5-HT(2C) Receptor Mutant Mice. Psychopharmacology (Berlin) 143 309-314.

Vickers SP, Benwell KR, Porter RH, Bickerdike MJ, Kennett GA \& Dourish CT 2000 Comparative Effects of Continuous Infusion of MCPP, Ro 60-0175 and D-Fenfluramine on Food Intake, Water Intake, Body Weight and Locomotor Activity in Rats. British Journal of Pharmacology 130 1305-1314.
Vickers SP, Dourish CT \& Kennett GA 2001 Evidence That Hypophagia Induced by D-Fenfluramine and D-Norfenfluramine in the Rat Is Mediated by 5-HT2C Receptors. Neuropharmacology $41200-209$.

Vickers SP, Easton N, Webster LJ, Wyatt A, Bickerdike MJ, Dourish GT \& Kennett GA 2003 Oral Administration of the 5-HT2 Creceptor Agonist, MCPP, Reduces Body Weight Gain in Rats Over 28 Days As a Result of Maintained Hypophagia. Psychopharmacology (Berlin) $167274-280$.

Walsh BT \& Devlin MJ 1998 Eating Disorders: Progress and Problems. Science 280 1387-1390.

Westberg L, Bah J, Rastam M, Gillberg C, Wentz E, Melke J, Hellstrand M \& Eriksson E 2002 Association Between a Polymorphism of the 5-HT2C Receptor and Weight Loss in Teenage Girls. Neuropsychopharmacology 26 789-793.

Wilckens T, Schweiger U \& Pirke KM 1992 Activation of 5-HT1C-Receptors Suppresses Excessive Wheel Running Induced by Semi-Starvation in the Rat. Psychopharmacology (Berl) 109 77-84.

Received in final form 11 November 2005

Accepted 21 November 2005

Made available online as an Accepted Preprint 24 November 2005 